\title{
Author Correction: Construction of Pd-Zn dual sites to enhance the performance for ethanol electro-oxidation reaction
}

Yajun Qiu, Jian Zhang (1), Jing Jin, Jiaqiang Sun, Haolin Tang, Qingqing Chen, Zedong Zhang, Wenming Sun (1), Ge Meng, Qi Xu, Youqi Zhu, Aijuan Han, Lin Gu (1), Dingsheng Wang (1) \& Yadong Li (D)

Correction to: Nature Communications https://doi.org/10.1038/s41467-021-25600-9, published online 6 September 2021.

In this article the wrong figure appeared as Supplementary Fig. 23; the figure should have appeared as shown below. The original article has been corrected. The incorrect figure remains present in the Transparent Peer Review file.

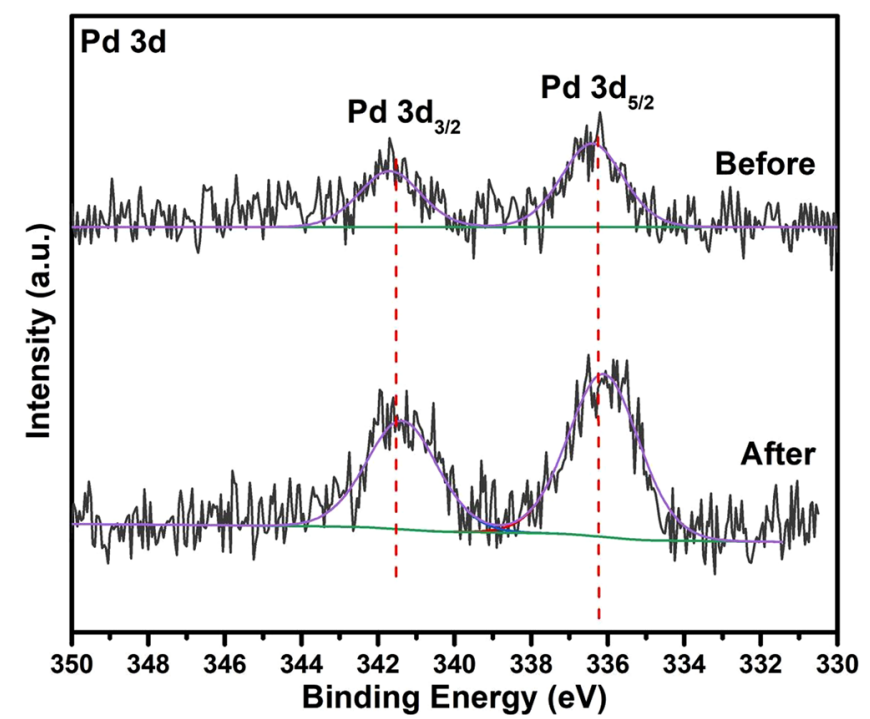

Published online: 11 February 2022

\section{Additional information}

Supplementary information The online version contains supplementary material available at https://doi.org/10.1038/s41467-022-28541-z.

(c) Open Access This article is licensed under a Creative Commons Attribution 4.0 International License, which permits use, sharing, adaptation, distribution and reproduction in any medium or format, as long as you give appropriate credit to the original author(s) and the source, provide a link to the Creative Commons license, and indicate if changes were made. The images or other third party material in this article are included in the article's Creative Commons license, unless indicated otherwise in a credit line to the material. If material is not included in the article's Creative Commons license and your intended use is not permitted by statutory regulation or exceeds the permitted use, you will need to obtain permission directly from the copyright holder. To view a copy of this license, visit http://creativecommons.org/licenses/by/4.0/. 